\title{
O uso do TuX Paint como ferRamenta de ensino e APRENDIZAGEM NAS SÉRIES INICIAIS DO ENSINO FUNDAMENTAL
}

\author{
THE USE OF TUX PAINT AS A TEACHING AND LEARNING TOOL IN \\ ELEMENTARY SCHOOL
}

DOI: 10.23926/RPD.2526-2149.2020.v5.n2.p1410-1427.id793

\section{Maria do Perpétuo Socorro Torres da Silva \\ Especialista em Letramento Digital (UEA) \\ Professora na Secretária \\ Municipal de Educação de \\ Coari/AM (SEMED- \\ COARI). \\ socorrots@hotmail.com}

\section{Francialan Souza dos \\ Santos}

Especialista em Mídias na

Educação (UFAM)

Professor na Instituto Federal

Amazonas (IFAM)

francialan.santos@ifam.edu. br

\section{Iracema Ramos \\ Martins}

Mestre em Letras (UFAM)

Professora no Instituto

Federal do Amazonas

(IFAM)

iracema_martins@ifam.edu. $\underline{\text { br }}$

\author{
Hudinilson Kendy de \\ Lima Yamaguchi \\ Mestre em Engenharia de \\ Produção (UFAM) \\ Professor no Instituto \\ Federal do Amazonas \\ (IFAM) \\ hkendy@ifam.edu.br
}

Resumo: No contexto educacional, a adoção de práticas pedagógicas inovadoras é uma realidade. Os métodos tradicionais de ensino vêm sendo substituídos por metodologias didáticas em que o aluno é o sujeito do processo construção do conhecimento. O objetivo desse artigo é utilizar o Tux Paint como ferramenta de ensino e aprendizagem para os alunos do primeiro ano do Ensino Fundamental de uma escola da rede pública na cidade de CoariAmazonas. A metodologia utilizada foi a pesquisa-ação, com recorte temporal transversal e coleta de dados qualitativa observacional. A pesquisa foi dividida em cinco etapas: diagnostico, planejamento, intervenção, avaliação e análise. Observarmos na pesquisa uma evolução no desenvolvimento logico dos alunos, evidenciando que o uso do software Tux Paint pode ser uma ferramenta útil no desenvolvimento cognitivo de crianças nesta faixa etária. Assim, os resultados demonstraram que o uso de ferramentas de Tecnologias de Informação e Comunicação - TIC demonstrou ser uma estratégia de ensino diferenciada para o desenvolvimento e potencialidades integral do aluno.

Palavras-chave: Ensino. TIC. Aprendizagem.

\begin{abstract}
Innovative pedagogical practices is a reality in the educational context, and traditional teaching methods are being replaced by innovative methodologies, where students develop knowledge for themselves. This paper aims to use Tux Paint as a teaching and learning tool for students in elementary education (first grade) to public school in Coari city, Amazon. Action research was method used, with a transversal technique and qualitative approach of data collection. The research was divided into five phases: diagnosis, planning, intervention, evaluation and analysis. We observe the evolution of logical development by students with Tux Paint software use. It could be a useful tool in the cognitive development for children in this age group. Thus, results reveal that the use of Information and Communication Technologies - ICT as pedagogical practices is differentiated teaching with successful approach to develop students to their full potential.
\end{abstract}

Keywords: Teaching. ICT. Learning. 


\section{INTRODUÇÃO}

O letramento digital envolve as práticas de leitura e escrita através da utilização das mídias e tecnologias digitais presentes no cotidiano das pessoas na sociedade atual que, segundo Araújo e Glotz (2009), fazem parte da vida de crianças e adultos, diariamente, e cada vez mais tornam-se uma necessidade de aprendizagem para que os cidadãos possam acompanhar as mudanças que vêm ocorrendo na contemporaneidade.

Os alunos, desde muito cedo, de acordo com os estudos de Da Silva; Da Silva Prates; Ribeiro (2016), já têm contato com os mais diversos meios de comunicação digital e de aplicativos e aparelhos modernos, já chegam à escola com interesse e disposição para utilizar essas ferramentas, e muitas vezes sabendo manusear inúmeras delas. Com isso, torna-se imprescindível a presença de práticas do letramento digital no cotidiano escolar, no processo de ensino e aprendizagem dos alunos.

Atualmente, a utilização da informática na educação como uma ferramenta didática vem crescendo, e esta utilização tem permitido a adoção de várias experiências de aprendizagem. "Na Educação Infantil, o papel da Informática é de potencializar o desenvolvimento intelectual, e paralelamente promover o desenvolvimento psicossocial da criança, uma vez que a coordenação motora esta está se estabelecendo concomitantemente às suas relações sociais" (BARBOSA E CHINA, 2017, p. 11) e "tratando-se especificamente da educação de crianças, o uso da tecnologia nas séries iniciais do Ensino Fundamental justifica-se e tem sua eficácia, pois criança desde o início de sua formação está inserida em uma sociedade tecnológica. (PEREIRA, 2020).

Esse estudo tem por objetivo desenvolver estratégias de intervenção para promover uma aprendizagem significativa através da utilização da ferramenta Tux Paint no processo de ensino com alunos do primeiro ano do Ensino Fundamental. Buscando, assim, "não apenas uma estratégia de diversificação das aulas, mas como uma ferramenta educacional que propicia um aprendizado significativo para os discentes através da intermediação tecnológica, utilizando recursos tecnológicos em sala de aula" (CUNHA; MESQUITA, 2017, p. 7).

A realização desse estudo justifica-se pela necessidade de demonstrar aos profissionais da educação a importância de inserir nas estratégias de ensino práticas diferenciadas que valorizem o gosto dos alunos e motivem o interesse dos mesmos pelas atividades elaboradas em sala de aula. Pois um dos grandes problemas encontrados no processo de ensino e aprendizagem nas séries iniciais do Ensino Fundamental é a falta de motivação, seja por parte dos alunos, seja por parte dos professores, desta forma a adoção de metodologias inovadoras, 
são artifícios pedagógicos que buscam superar o tradicionalismo das aulas e minimizar o processo de evasão escolar, a monotonia da sala de aula que geram a retenção escolar. (SANTOS; MORAES; LIMA, 2108).

Os alunos "vislumbram o acesso às ferramentas digitais sentindo-se incluídos, digital e socialmente, à medida que utilizam o computador como recurso multimídia para interagir em comunidades virtuais e pesquisar; enfim, aprender, efetivamente" (FERNANDES, 2011, p. 4).

Para tanto, o uso das estratégias pedagógicas diferenciadas permite, ao educador, superar os desafios do processo de aprendizagem e letramento de crianças, desenvolvendo assim práticas e estratégias para garantia do sucesso das diversas aprendizagens. Desta forma, a escolha de "softwares educativos na alfabetização tem se mostrado eficaz no desenvolvimento e aprimoramento da leitura e escrita. Nesta perspectiva, este trabalho orientou-se pelo uso do Tux Paint, que é um editor de imagens de código aberto, para crianças que operem o mouse" (PINHEIRO; PINHEIRO, 2017, p. 17).

Considerando a retórica da investigação, Pereira (2020) afirmar que toda criança tem o direito de aprender dentro de seu tempo e de forma lúdica, e as TIC são excelentes recursos que possibilitam esse desenvolvimento, pois, sendo bem planejado, elas unem a tecnologia ao processo educativo. A exemplo dos estudos de Barbosa; China (2017); Policarpo; Fuhr; Librelotto (2019); Xabregas; Brasileiro (2019) e Pescador; Valentini (2019), que desenvolveram suas pesquisas utilizando as TIC, de forma especifica o software Tux Paint, como ferramentas facilitadoras de ensino e aprendizagem para as séries iniciais do Ensino Fundamental.

\section{Referencial Té́RICO}

\subsection{As SÉries INICIAIS do ENSINo FundaMentaL}

É previsto em lei a gratuidade do ensino regular, e de acordo com a Lei de Diretrizes e Bases da Educação Nacional - LDB (Lei 9.394/96), em seu artigo 32, garante Ensino Fundamental obrigatório, iniciando aos 6 (seis) anos de idade da criança, tendo por objetivo principal o desenvolvimento da capacidade de aprender, a partir do pleno domínio da leitura, da escrita e do cálculo, logo o processo de alfabetização começa de fato por volta dos 6 a 7 anos. (BRASIL, 1996).

Ao ingressar nos anos iniciais do Ensino Fundamental, as crianças já devem ter seus primeiros contatos com as práticas de leitura e escrita (DE SOUSA; BERNARDINO, 2011). 
Nos últimos anos, foram desenvolvidas diversas ações e tomadas diversas iniciativas para estimular e garantir a alfabetização nos primeiros anos de escolaridade (SANTOS; ALMEIDA; ZANOTELLO, 2018).

Segundo Diese; Baldez; Martins, (2017), o aluno possui um papel ativo no seu processo de ensino e aprendizagem, atuando como protagonista, e assim interagindo com os diversos conteúdos ministrados em sala de aula, seja ouvindo, falando ou perguntando e discutindo, ele estará exercitando as suas diferentes habilidades, e não apenas ouvindo aulas expositivas, muitas vezes mais monologadas que dialogadas. Corroborando com os autores, Arruda et al (2017) atribuem com este papel de protagonismo do aluno no seu processo de aprendizagem à constante evolução da aprendizagem, e assim os alunos que estão iniciando a sua vida escolar, poderão vivenciar e ultrapassar situações, funções e papéis de sua vida futura.

\footnotetext{
Porém, em função dos grandes avanços tecnológicos e científicos vivenciados atualmente, torna-se desafiador ensinar os conteúdos desse componente curricular, sobretudo para os professores das séries iniciais, que possuem papel relevante no processo de organização dos conhecimentos escolares. Eles não devem apenas reproduzir conhecimentos, mas sim produzi-los quando os organizam para públicos específicos em suas salas de aula. (SILVA; SANTOS, 2017, p. 1).
}

É indiscutível a necessidade do desenvolvimento de práticas educacionais inovadoras e a adoção de recursos pedagógicos para o processo de ensino e aprendizagem. E neste contexto as TIC são apresentadas como uma importante ferramenta facilitadora para o professor que pode utilizá-las das mais diversas formas conforme apresentam: Silva, Dos Santos (2017); Souza, et al. (2017); Santos, Almeida, Zanotello (2018); Coelho (2019) e Pereira (2020), as diversas formas de utilização nas séries iniciais do Ensino Fundamental, pois estas ferramentas, segundo os autores, são grandes aliadas para auxiliar a compreensão do aluno.

\subsection{Letramento Digital E as TeCnOlogias de INFORMaÇão E COMUNiCAÇÃo - TIC}

As habilidades de leitura e escrita no Brasil passaram muito tempo ligadas ao conceito de alfabetização, ao surgirem novas demandas de práticas de leitura e escrita no país, passouse a utilizar o termo letramento que, segundo Rezende (2016), vai além da decodificação de sinais gráficos, relacionando a leitura e a escrita às práticas sociais, ao conhecimento de mundo, Melo (2012) destaca que o letramento escolar surgiu para complementar a alfabetização dos alunos, não limitando-se somente à compreensão da leitura e da escrita, mas complementando o aprendizado, relacionando-se ao conhecimento de mundo e seus aspectos econômicos, sociais e culturais. 
Atualmente as práticas de leitura e escrita podem ser mediadas pelas tecnologias digitais, posto à diversidade e possibilidades de comunicação oral e escrita que são oportunizadas às pessoas, pela era digital. Dessa forma, Moura; Mion; Carvalho, (2019) relatam que o letramento está inserido nas práticas digitais do nosso cotidiano, de acordo com a definição de letramentos digitais que:

[...] são conjuntos de letramentos (práticas sociais) que se apoiam, entrelaçam e apropriam mútua e continuamente por meio de dispositivos digitais para finalidades específicas, tanto em contextos socioculturais, geograficamente e temporalmente limitados, quanto naqueles construídos pela interação mediada eletronicamente (BUZATO, 2009, p. 16).

O letramento digital envolve, além das habilidades de comunicação e das formas de manusear um dispositivo, as tecnologias digitais que exigem pensamentos críticos de quem está utilizando, e habilidades para realizar questionamentos e desenvolver o pensamento crítico (REZENDE, 2016). Além das práticas de leitura e escrita nos ambientes digitais, o letramento digital possibilita o acesso aos mais diversos meios de comunicação, de gêneros discursivos e de informações para a formação do conhecimento de mundo dos usuários.

Diante desses novos meios de comunicação digital das formas de interação social, é importante, segundo Azevedo; Gasque (2017), que o letramento digital se faça presente desde a Educação Infantil, para que as crianças, que em sua maioria, já possuam contato com as tecnologias digitais, tenham oportunidade de aprender novos conceitos e conteúdos a partir desses instrumentos, aprender de forma pedagógica, instruídos pelo professor, para que as atividades sejam monitoradas e possam alcançar os objetivos propostos pelo professor.

O uso do computador na instituição de ensino, por exemplo, não promove, por si só, alterações nos métodos pedagógicos e não permite que a criança tenha acesso de maneira adequada a uma metodologia de ensino, para isso, é necessária a intermediação do professor.

Os computadores [...] "podem ser utilizados tanto para a leitura e edição mecânica e descontextualizada de gêneros tradicionalmente valorizados pela escola, quanto para promover práticas diversificadas de usos sociais da leitura e escrita no contexto escolar" (SANTOS, 2015, p. 9). O autor contribui ao afirmar que os computadores podem servir como instrumento de ensino para os professores, pois permitem o acesso a diversos gêneros discursivos, ampliando as práticas de letramento das crianças e uma pluralidade de acesso a conteúdo e informações relevantes para promover seu letramento digital. É importante ressaltar que:

o uso da tecnologia digital [...] transformou a natureza da comunicação escrita e o letramento convencional, introduzindo novos gêneros textuais, práticas discursivas e estabelecendo um novo paradigma nas ciências da linguagem (VIEIRA, 2005, p. 19). 
Por isso, é necessário ressaltar a importância das tecnologias digitais no processo de ensino e aprendizagem, pois é um direito da criança em sua formação cidadã e social estar desenvolvendo práticas cotidianas, que fazem parte de sua realidade.

Além disso, as TIC, permitem que a criança desenvolva diversas habilidades como leitura, escrita, comunicação oral, acesso aos diversos gêneros discursivos etc., ampliando sua prática de letramento digital. Pois:

O uso consciente das TIC com intencionalidade pedagógica envolve reflexão sobre os motivos para utilizar determinado recurso e em que áreas do currículo faz sentido utilizá-lo, o que implica pensar quais objetivos e aprendizagens específicas devem ser desenvolvidas. (SANTOS; ALMEIDA; ZANOTELLO, 2018, p. 335).

Assim, o uso das TIC pode aproximar o conteúdo de estudo com a vida cotidiana da criança, despertando nela não só o desejo de estabelecer comunicações, produzir e publicar histórias, contar acontecimentos do seu cotidiano, trocar experiências, como também desenvolver o prazer pela leitura e escrita. (SOUZA, et al. 2017, p. 49)

\subsection{Ferramenta Tux Paint PARA O PROCESSO de ENSINO E APRENDIZAGEM}

O Tux Paint é um software de desenho destinado ao público infantil (3 à 12 anos) alfabetizadas ou não, essa ferramenta possui uma interface simples e acessível, com efeitos sonoros variados além de apresentar uma tela em branco, com um mascote, que orienta os usuários a utilizarem o programa, as ferramentas são de fácil manuseio para que qualquer usuário consiga manusear e criar seus desenhos. (PEREIRA; MARTINS, 2016). Além disso, é uma ferramenta compatível com o sistema operacional livre Linux, sendo bastante utilizado em instituições de ensino.

Esta ferramenta, o Tux Paint, é de fácil manuseio e, segundo Dos Santos; Gitahy (2017), permite que os alunos explorem suas leituras de mundo, dividam experiências e conhecimentos e demonstrem o grau de aprendizagem em que estão e o que ainda precisam aprender. A partir desta ferramenta, foi realizada uma intervenção pedagógica, utilizando a ferramenta Tux Paint para iniciar o processo de letramento digital com alunos do $1^{\circ}$ ano do Ensino Fundamental, de uma escola da rede Estadual da cidade de Coari-AM, com alunos com faixa etária de seis a sete anos de idade.

\section{Metodologia}

A metodologia desenvolvida nesta pesquisa foi a Pesquisa-ação, opção metodológica defendida por vários estudiosos sobre o uso de TIC nas séries iniciais do Ensino Fundamental, tais como Cartaxo (2016); Leite (2016); De Souza, et al. (2017) e Daltoé, et al. (2019). 
Esta metodologia propõe aos sujeitos envolvidos na pesquisa uma mudança ou aprimoramento das atuais práticas pedagógicas (SEVERINO, 2016), está metodologias é muito utilizada em pesquisas educacionais, por não ter a "pretensão apenas de compreender ou descrever o mundo da prática, mas de transformá-lo" (KINCHELOE, 1997, p. 179).

Neste contexto educacional, "a criança é concebida como ator social, propondo que suas experiências constituam o centro do planejamento e que a proposta curricular inclua a participação da criança.” (COLASANTO, 2016, p. 332), em paralelo à Tecnologia Digital, com finalidades pedagógicas, apresenta-se como uma ferramenta facilitadora e significativa nos processos de ensino e aprendizagem (MELO, 2019).

A abordagem desta pesquisa é qualitativa, pois a sua finalidade é apresentar uma perspectiva não visível, evidenciando os aspectos da realidade que não podem ser quantificados, centrando-se na compreensão e nas interações dos alunos a partir do desenvolvimento da intervenção pedagógica. Nesta pesquisa, os dados foram analisados subjetivamente pelos pesquisadores com foco na evolução das atividades e na percepção das dinâmicas e relações educacionais presentes no contexto da pesquisa (RHODEN; ZANCAN, 2020).

\subsection{LOCAL E CONTEXTO DA PESQUISA}

A pesquisa ocorreu em uma escola da rede pública estadual de ensino, na cidade de Coari-Amazonas, que funciona no turno diurno, atendendo turmas de educação infantil. O censo escolar de 2018, registou 307 alunos nas séries iniciais $\left(1^{\mathrm{a}}\right.$ a $4^{\mathrm{a}}$ série ou $1^{\mathrm{o}}$ ao $5^{\mathrm{o}}$ ano). (INEP, 2018).

\subsection{SuJEITOS DA PESQUISA E INSTRUMENTO DE COLETA DE DADOS}

Os sujeitos da pesquisa foram os 25 alunos do $1^{\circ}$ ano do Ensino Fundamental, com idade entre 6 e 7 anos. Para desenvolvimento da pesquisa, optou-se pela observação participante de forma qualitativa, ponderando a evolução e desenvolvimento das atividades realizadas pelos alunos. Nesta pesquisa, os proponentes da observação participante apelam para a imersão do investigador no cotidiano da sala de aula. Assim, o "pesquisador colocar-se numa postura de identificação com os pesquisados” (SEVERINO, 2016, p. 120).

\subsection{Desenho da Pesquisa}

A pesquisa foi desenvolvida obedecendo as seguintes etapas de execução: diagnóstico a partir da observação da situação-problema; planejamento das ações com a escolha do material e dinâmicas a serem executadas; intervenção a partir da aplicação da proposta pedagógica; 
avaliação onde foi realizada a discussão sobre as atividades com os alunos e feedback, por fim a reflexão com a análise e compreensão dos resultados (DAVISON; MARTINSONS; KOCK; 2004). Ao final de cada ciclo, retornamos à primeira etapa com o objetivo de reavaliar o diagnóstico e iniciar o novo ciclo da pesquisa. (THIOLLENT, 2011).

\section{ANÁlise dos Dados}

O letramento digital, além de ser uma das possibilidades de aperfeiçoamento nas práticas de leitura e escrita para o ensino e aprendizagem para a educação infantil, permite a inserção do aluno no mundo da tecnologia digital, que também representa o domínio para utilização de técnicas e habilidades para usar os mais diversos tipos de mídias presentes no mundo digital. (MOREIRA, 2012).

Tais mudanças são acessíveis, tendo em vista que "Os recursos tecnológicos estão disponíveis para a sociedade e o importante é utilizá-los de maneira consciente e de forma didática e o [...] importante é transmitir o conteúdo de forma clara" (MOREIRA, 2012, p. 12). Abordagens pedagógicas diferenciadas no processo de ensino e aprendizagem de letramento digital são fundamentais para a promoção de uma aprendizagem significativa (DA SILVA, 2018).

\subsection{Diagnóstico}

Nesta etapa, foi realizado um levantamento exploratório (FILIPPO; ROQUE; PEDROSA, 2018) para identificação dos problemas de aprendizagem e integração dos alunos da educação infantil conforme relatam Paiva, et al. (2016); Piscinato, De Oliveira (2017) e Gomes, Alves (2019). O diagnóstico foi realizado colaborativamente pelos pesquisadores, considerando que um dos pesquisadores atua como professora na turma envolvida na pesquisa. Nesta etapa foi constatada a necessidade de desenvolver uma atividade lúdica utilizando as Tecnologias de Informação e Comunicação - TIC, referendado pelos trabalhos de Pereira, de Lima, Moreira, (2019); Tonin; Matos, (2018) e Andrade; Oliveira, (2017).

No mundo contemporâneo da era digital, onde as crianças já nascem como nativos digitais (PESCADOR, 2010), o uso das TIC devem ser utilizadas como recursos para a aprendizagem dos alunos, obviamente tendo o seu uso adequado para o desenvolvimento do processo educacional, (MARTINS, 2017) para que o educando possa compreender o mundo ao seu redor e como as tecnologias, como um dos fenômenos de seu tempo, relacionando-se com sua experiência de viver em um mundo de mudanças constantes. 
E assim, o diagnóstico desta pesquisa foi instituído para a próxima etapa da pesquisa que foi o planejamento das atividades pedagógicas.

\subsection{Planejamento}

O planejamento das ações foi realizado visando promover um aprendizado significativo a partir da adoção de "práticas pedagógicas utilizando as TIC quem influenciam no processo de aprendizagem das crianças da educação infantil" (PINTO; MENEZES, 2017, p. 1845). Nesta proposta os pesquisadores assumem o papel de professores na condição de mediadores do conhecimento, auxiliando a interação da criança com o mundo.

Foram definidas as seguintes etapas para exclusão das ações: visita para conhecer a estrutura, verificar as providências necessárias para organização do laboratório de informática; escolha da TIC adequada para faixa etária dos alunos envolvidos na pesquisa e a escolha dos conteúdos que deveriam ser trabalhados em sala de aula.

Nesta etapa, também foi definido o cronograma de atividades, que seria realizado uma atividade por semana, e a forma de coleta das informações, que foi baseado na observação da interação das crianças com a TIC, (GOMES; DA LUZ, 2019) e a evolução da aprendizagem delas, baseando-se no desenvolvimento e percepção das atividades propostas.

\subsection{INTERVENÇÃO}

A pesquisa foi realizada no primeiro semestre de 2019, foram realizados oito encontros, nos meses de maio e junho. Nos primeiros encontros, foi apresentado aos alunos a apresentação e leitura do poema “O Girassol” de Vinicius de Moraes, (MORAES, 2004, p. 19), este poema foi escolhido por possuir um grande valor simbólico, pois “essa planta simboliza o Sol que gira e a luz móvel de que o Sol é a fonte". (CHEVALIER; GHEERBRANT, 2012, p. 485). Em seguida foram apresentadas ilustrações associadas ao poema como: céu, carrossel, girassol, abelhas e borboletas, em seguida foram propostas atividades relacionadas ao cotidiano dos alunos, por meio de desenhos e pinturas com prioridade no lúdico.

Nos encontros 3, 4 e 5, com 50 minutos cada, os pesquisadores acompanharam os alunos até o laboratório de informática e apresentaram o Tux Paint, trata de um software livre integrante do projeto Tux4Kids, este software foi desenvolvido para criação de desenhos e montagem de figuras, (UFRPE; SME GARANHUNS, 2019).

Estes encontros foram exclusivos para explicar aos alunos a utilização da ferramenta Tux Paint, eles utilizaram individualmente um computador e foram orientados ao uso software, 
utilizando as ferramentas suas funcionalidades como: o pincel, a cor, a espessura do pincel, a utilizar a borracha, bem como as mais diversas ferramentas do software.

Os alunos apresentaram muitas dúvidas, principalmente, em relação a iniciar a utilização do aplicativo e usar a borracha para apagar o que eles fizeram. Essas dúvidas foram surgindo e sendo sanadas no decorrer da atividade. Para tanto, observou-se o comportamento curioso e atento dos alunos enquanto eles manipulavam a ferramenta e usavam os computadores.

Através destas atividades, pudemos observar a coordenação motora e o raciocínio lógico dos alunos, além de promover os primeiros contatos com a tecnologia. No decorrer desta etapa, as crianças demonstraram-se curiosas e muito atenciosas as explicações, um fator positivo para a efetividade da proposta. (SANTOS, 2019).

Nos encontros 6 e 7, no laboratório de informática, os alunos receberam novamente a leitura do poema "O Girassol" de Vinicius de Moraes, (MORAES, 2004, p. 19), para que fizessem novamente as ilustrações com base no poema que lemos, só que desta vez utilizando o software, para desenhar e inserir textos, de acordo com a imaginação deles permitissem, os alunos desenvolveram estas atividades em dois encontros de 50 minutos cada. Alguns alunos $32 \%(\mathrm{~N}=8)$, apresentaram certas dificuldades com a utilização das ferramentas no início das atividades, mas estas limitações foram sanadas no decorrer da atividade. A outra parcela dos alunos $68 \%(\mathrm{~N}=17)$ conseguiram utilizar com mais facilidade o software para a produção do desenho.

\subsection{Avaliar}

No $8^{\circ}$ encontro, foi realizada a análise e discussão do aprendizado. Nesta etapa da pesquisa foi realizada a avaliação da utilização do Tux Paint como ferramenta de ensino e aprendizagem para os alunos, a partir desta reunião que pudemos identificar e referendar as constatações observadas nos encontros anteriores, a partir do feedback dos alunos quanto aos objetivos da atividade que era de explorar a coordenação motora, a orientação do espaço, utilização de cores e assimilação dos conteúdos.

Por fim, foi disponibilizado um período para a arguição dos alunos sobre a importância e compreensão deles sobre a utilização da ferramenta Tux Paint, para expressar as suas percepções sobre o poema e desenvolver as atividades pedagógicas de forma diferente do cotidiano em sala de aula. 


\subsection{REFLETIR}

A reflexão sobre as atividades e os resultados obtidos finaliza atividade de campo, pois como as contribuições foram satisfatórias, do ponto de vista observacional, decidiu-se por finalizar a pesquisa, por se tratar de um recorde temporal transversal, pois envolveu a coleta da percepção dos 25 alunos do $1^{\circ}$ ano do Ensino Fundamental, somente no período da pesquisa (MALHOTRA, 2019), representando assim uma fotografia temporal do Ensino Fundamental, desta turma e desta escola específica, podendo ser replicado para outros estudos (COOPER; SCHINDLER, 2016).

\section{Resultados e Discussão}

As crianças são muito espontâneas e criativas e gostaram das atividades elaboradas no laboratório de informática e dialogaram sobre o uso de outras ferramentas. Em consonância com Pinto; Menezes, (2017); Camargo, et al., (2016) e Leite, (2016), as crianças gostam de mexer nos comutadores na escola e principalmente em casa, pois as ferramentas de informática já fazem parte do seu cotidiano (PESCADOR, 2010). Logo atividades desta natureza proporcionam a eles oportunidade de expandir conhecimento e buscar novas formas de aprendizagem e prática da leitura e da escrita. (FERNANDES, 2016).

No decorrer desta pesquisa, ficou evidente e notório a intimidade que as crianças possuem com as ferramentas digitais e, apesar dos alunos ainda não possuirem domínio total da leitura e da escrita, a adoção de práticas diferenciadas de ensino são importante para se obter resultados satisfatórios de aprendizagem, Santos (2019), em sua pesquisa, relata que as atividades pedagógicas que as crianças participaram ativamente, mesmo os alunos que nunca utilizaram o computador, tiveram um bom desempenho.

Neste contexto, o uso das TIC, segundo Andrade e Oliveira (2017), influencia na construção de métodos diferentes para o processo de ensino e aprendizagem dos alunos, e o “computador é uma ferramenta, com recursos multimídias quem oferece possibilidades de exploração pedagógica de uma simultaneidade de linguagens que pode conduzir a determinadas análises da linguagem escrita no processo de alfabetização" (FRADE, 2017, p. 79), substanciando o que foi observado na pesquisa que a adoção de atividades diferenciadas tornam o ensino mais eficaz, mais significativo aos alunos, que ainda estão aprendendo a ler e escrever.

Durante a realização das aulas, também foi possível observar que alguns alunos tiveram certas dificuldades para utilização da ferramenta Tux Paint no início da atividade, adversidade esta considerada normal, pois é de "fundamental importância entender que a aprendizagem é 
gradativa, e que quanto mais a criança associar a leitura e a escrita com atividades úteis e que lhe deem prazer”, (GARCIA, 2016, p. 39), mais célere será o aprendizado da criança.

A facilidade de acesso e acessibilidade do software Tux Paint permitiu que as crianças interagissem de maneira eficaz, pois através da ludicidade e do conhecimento do mundo digital os alunos puderam exploraram várias ferramentas que o software possui, demonstrando a curiosidade e o interesse dos alunos em realizar a atividade proposta.

Eles souberam relacionar bem as cores do girassol, por conhecerem a flor, sentiram mais facilidade em desenhar algo sobre o girassol, nenhum aluno fez desenho sobre roda, carrossel ou outros elementos do poema.

\section{CONCluSÃo}

A realização desse estudo demonsta a importância da promoção de estratégias de ensino inovadoras, seja através de práticas diferenciadas ou com a utilização das TIC no processo de ensino e aprendizagem. A adoção de estratégias de ensino que facilitam o acesso à informação potencializa novas oportunidades para aprender e novas formas de ensinar, como os mecanismos de conhecimento e emoção que permeiam a aprendizagem.

Assim, constatamos que o uso do software Tux Paint como ferramenta de ensino e aprendizagem para os alunos do primeiro ano do Ensino Fundamental da rede pública de uma escola na cidade de Coari-Amazonas contribui para o processo de integração das crianças com as mídias digitais, e estes recursos tecnológicos estimularam as percepções dos alunos, tornando as práticas pedagógica mais dinâmicas, elencando as TIC como ferramentas pedagógicas para o letramento e aquisição de aprendizagens significativas na Educação Básica, desde que associada a ações proativas que aproximem a realidade dos alunos aos novos conhecimentos.

\section{REFERÊNCIAS}

ANDRADE, Gustavo Oliveira; OLIVEIRA, Vinicius Campos de. Informática na educação: um olhar sobre a utilização das novas tecnologias no processo de ensinoaprendizagem. Educação, Cultura e Comunicação, v. 8, n. 15, p. 159-170, 2017. ISSN Eletrônico: 2177-5087. Disponível em: http://unifatea.com.br/seer3/index.php/ECCOM/article/view/471/421. Acesso em 22 jun. 2020.

ARAÚJO, Verônica Danieli Lima; GLOTZ, Raquel Elza Oliveira. O letramento digital enquanto instrumento de inclusão social e democratização do conhecimento: desafios atuais. Revista Paidéi@-Revista Científica de Educação a Distância, v. 2, n. 1, p. 1-26, 2009. ISSN:1982-6109, disponível em: 
https://periodicosunimes.unimesvirtual.com.br/index.php/paideia/article/view/85/50. Acesso em 12 jun. 2020.

ARRUDA, Juliana et al. Tecnologias digitais e o processo de protagonismo estudantil no Ensino Fundamental. In: VI Congresso Brasileiro de Informática na Educação (CBIE 2017). Anais do XXIII Workshop de Informática na Escola (WIE 2017). 2017.

AZEVEDO, Isabel Cristina Michelan de; GASQUE, Kelley Cristine Gonçalves Dias. Contribuições dos letramentos digital e informacional na sociedade contemporânea. Transinformação, Campinas, v. 29, n. 2, p. 163-173, maio/ago. 2017. Disponível em: http://www.scielo.br/scielo.php?script=sci_arttext\&pid=S010337862017000200163\&lng=en\&nrm=iso. Acesso em: 18 mai. 2020.

BARBOSA, Fernanda de Arruda Campos; CHINA, Anna Patricia Zakem. Aulas de Informática na Grade Curricular da Educação Infantil e Ensino Fundamental. Revista Interface Tecnológica, v. 14, n. 1, p. 9-20, 2017. ISSN On-line 2447-0864. Disponível em: https://revista.fatectq.edu.br/index.php/interfacetecnologica/article/view/146. Acesso em 22 jun. 2020.

BRASIL. Lei 9394/96 de Diretrizes e Bases da Educação Nacional. 1996. Disponível http://www.planalto.gov.br/ccivil_03/leis/19394. Acesso em: 14 jun. 2020.

BUZATO, Marcelo El Khouri. Letramento e Inclusão: Do Estado-Nação à Era das TIC. UFGD/ Unicamp: São Paulo, DELTA: Documentação de Estudos em Lingüística Teórica e Aplicada, vol. 25, n. 1, p. 1-18, 2009. ISSN 1678-460X. Disponível em: https://www.scielo.br/scielo.php?script=sci_arttext\&pid=S010244502009000100001\&lng=pt\&nrm=iso. Acesso em 12 mai. 2020.

CAMARGO, Guilherme et al. Informática na Escola: Experiência de Apoio ao Uso de Recursos de Informática na Educação Infantil. Anais do Salão Internacional de Ensino, Pesquisa e Extensão, v. 8, n. 3, 2016.

CARTAXO, Rubens Dantas. O uso das tecnologias de informação e comunicação pelos professores das séries iniciais do Ensino Fundamental. 2016. 25f. Trabalho de Conclusão de Curso (Graduação em Pedagogia), Centro de Educação, Universidade Federal do Rio Grande do Norte, Natal, 2016.

CHEVALIER, Jean. GHEERBRANT, Alain. Dicionário de símbolos: mitos, sonhos, costumes, formas, figuras, cores, números. Trad. Vera da Costa e Silva [et al.]. Rio de Janeiro: José Olympio, 2012.

COELHO, Dalilla Conceição. Educação física nos anos iniciais do ensino fundamental: cenários, dificuldades e desafios. 2019. 47 f. Monografia (Graduação) - Curso de Educação Física, UFT, Tocantinópolis, 2019.

COLASANTO, Cristina Aparecida. A criança protagonista no currículo e na própria avaliação: uma pesquisa-ação realizada em duas escolas municipais de educação infantil de São Paulo. Revista e-Curriculum, v. 14, n. 1, p. 332-356, 2016. ISSN: 1809-3876. Disponível em: https://www.redalyc.org/pdf/766/76645155018.pdf. Acesso em 15 jun. 2020. 
COOPER, Donald R.; SCHINDLER, Pamela S. Métodos de pesquisa em administração. 12. ed. Porto Alegre: AMGH, 2016.

CUNHA, Simone Silva; MESQUITA, Suely da Silva. O uso do Chroma Key como recurso pedagógico: explorando os contos de medo. Revista do Seminário Mídias \& Educação, v. 3, n.1, 2017. ISSN 2526-9070. Disponível em:

http://cp2.g12.br/ojs/index.php/midiaseeducacao/article/view/1463/1049. Acesso em 15 mar. 2020.

DA SILVA, Dilcinho Luiz. Letramento Digital e Aprendizagens Significativas na Educação Básica. CIET:EnPED, [S.1.], maio 2018. ISSN 2316-8722. Disponível em: https://cietenped.ufscar.br/submissao/index.php/2018/article/view/472. Acesso em: 20 ago. 2020.

DA SILVA, Ione de Cássia Soares; DA SILVA PRATES, Tatiane; RIBEIRO, Lucineide Fonseca Silva. As Novas Tecnologias e aprendizagem: desafios enfrentados pelo professor na sala de aula. Em Debate, n. 15, p. 107-123, 2016. ISSNe 1980-3532. Disponível em: https://periodicos.ufsc.br/index.php/emdebate/article/view/1980-3532.2016n15p107. Acesso em 13 ago. 2020.

DALTOÉ, Thaís; ROVEDA, Crislaine de Anunciação; FREITAS, Fabrício; SILVA, João Alberto da. Uso de tecnologias no ensino de Matemática nos Anos Iniciais do Ensino Fundamental: um Estado da Arte. RELACult-Revista Latino-Americana de Estudos em Cultura e Sociedade, v. 5, n. 4, p. 1-13, 2019. e-ISSN: 2525-7870. Disponível em: http://periodicos.claec.org/index.php/relacult/article/view/1254/807. Acesso em 17 ago. 2020.

DE SOUSA, Linete Oliveira; BERNARDINO, Andreza Dalla. A contação de histórias como estratégia pedagógica na educação infantil e ensino fundamental. Educere et Educare, v. 6, n. 12, p. 235-249, 2011. e-ISSN 1981-4712. Disponível em: http://erevista.unioeste.br/index.php/educereeteducare/article/view/4643/4891. Acesso em 18 ago. 2020.

DOS SANTOS, Dilma Pereira; GITAHY, Raquel Rosan Christino. O Uso do Objeto de Aprendizagem Tux Paint na Produção Escrita em Língua Portuguesa com Alunos Surdos. Revista Pleiade, v. 11, n. 21, p. 32-38, 2017.

DOI: https://doi.org/10.32915/pleiade.v13i29. Disponível em: https://pleiade.uniamerica.br/index.php/pleiade/article/view/332/415. Acesso em 9 abr. 2020.

FERNANDES, Jaiza Helena Moisés. Software livre na educação para além da inclusão digital e social: Letramentos Múltiplos de Professores e Alunos. Texto Livre: linguagem e tecnologia, v. 4, n. 1, p. 2-15, 2011. ISSN 1983-3652. Disponível em: http://www.periodicos.letras.ufmg.br/index.php/textolivre/article/view/88/7277. Acesso em 15 ago. 2020.

FERNANDES, Naiara de Souza. A informática na escola: o uso do computador como recurso nos anos iniciais do ensino fundamental. Anais do Simpósio Linguagens e Identidades da/na Amazônia Sul-Ocidental, n. 1, 2016.

FILIPPO, Denise; ROQUE, Gianna; PEDROSA, Stella. Pesquisa-ação: possibilidades para a Informática Educativa. in Metodologia de Pesquisa Científica em Informática na 
Educação: Abordagem qualitativa de Pesquisa. Volume 3. Comissão Especial de Informática na Educação, Sociedade Brasileira de Computação, 2018.

GARCIA, Marcelo Bechtlufft. Tecnologias, currículo e cultura digital na prática de alfabetizar nos anos iniciais. 2016. 50f. Trabalho de Conclusão de Curso (Especialização em Educação na Cultura Digital), Universidade Federal de Santa Catarina. Centro de Ciências da Educação. Departamento de Metodologia de Ensino. Educação na Cultura Digital. Florianópolis - SC, 2016.

GOMES, Núbia Rosetti Nascimento; ALVES, Edson Pantaleão. Educação Infantil em Tempo Integral no Município de Vitória/ES: modos de organização e concepções. InterMeio:

Revista do Programa de Pós-Graduação em Educação-UFMS, v. 25, n. 50, p. 203-220, 2019. ISSN 2674-9947. Disponível em: https://periodicos.ufms.br/index.php/intm/article/view/9425. Acesso em 14 jun. 2020.

GOMES, Veronete Dias; DA LUZ, Marcondes Oliveira. Tecnologias da Informação e Comunicação no Processo da Alfabetização. Educação \& Tecnologia, v. 23, n. 1, p. 22-30. 2019. ISSN Eletrônico 2317 - 7756. Disponível em: https://periodicos.cefetmg.br/index.php/revista-et/article/view/805. Acesso em 16 ago. 2020.

\section{INSTITUTO NACIONAL DE ESTUDOS E PESQUISAS EDUCACIONAIS ANÍSIO} TEIXEIRA - INEP. EE Iraci Leitão. Qedu, 2018. Disponível em $<$ https://www.qedu.org.br/escola/8346-ee-iraci-leitao/censo-escolar>. Acesso em 24 ago. 2020.

KINCHELOE, J. A formação do professor como compromisso político: mapeando o pósmoderno. Porto Alegre: Artes Médicas, 1997.

LEITE, Élison Alves. O uso da sala de informática como recurso didático-pedagógico na Educação Infantil e séries iniciais do Ensino Fundamental. 2016. 38f. Trabalho de Conclusão de Curso (Graduação em Pedagogia), Centro de Educação, Universidade Federal do Rio Grande do Norte, Martins, 2016.

MALHOTRA, Naresh K. Pesquisa de marketing: uma orientação aplicada. 7. ed. Porto Alegre: Bookman, 2019.

MARTINS, Viviane Lima. Tecnologia de Informação e Comunicação (TIC) e Educação. Revista Científica Intr@ ciência, v. 13, n. 1, p. 1-11, 2017. ISSN 2177-3645. Disponível em: http://uniesp.edu.br/sites/_biblioteca/revistas/20170710083906.pdf. Acesso em 16 ago. 2020.

MELO, Ariane da Silva Wanderley. A utilização da tecnologia digital na educação infantil. 2019. 50 f. Trabalho de Conclusão de Curso (Licenciatura em Pedagogia) - Unidade Acadêmica de Garanhuns, Universidade Federal Rural de Pernambuco, Garanhuns, 2019.

MELO, Terezinha Toledo Melquiades de. A alfabetização na perspectiva do letramento: a experiência de uma prática pedagógica no $2^{\circ}$ ano do ensino fundamental. 2012. $108 \mathrm{f}$. Dissertação (mestrado em Educação) - Universidade Federal de Juiz de Fora da Faculdade de Educação do Programa de Pós-Graduação em Educação, Juiz de Fora, Minas Gerais, 2012. 
MORAES, Vinícius de. O Girassol. 2004. Disponível em: https://www.letras.mus.br/vinicius-de-moraes/87235. Acesso em: 12 jun. 2020.

MOREIRA, Carla. Letramento digital: do conceito à prática. Anais do SIELP, v. 2, n. 1, p. 115, 2012. ISSN 2237-8758. Disponível em: http://www.ileel.ufu.br/anaisdosielp/wpcontent/uploads/2014/06/volume_2_artigo_051.pdf. Acesso em 21 ago. 2020.

MOURA, Késsia De Paulo; MION, Mirian; CARVALHO, Marie Jane Soares. O Letramento Digital na Formação de Professores: uma revisão sistemática das produções. In: Brazilian Symposium on Computers in Education (Simpósio Brasileiro de Informática na EducaçãoSBIE). 2019. p. 606.

PAIVA, Marlla Rúbya Ferreira et al. Metodologias ativas de ensino-aprendizagem: revisão integrativa. SANARE-Revista de Políticas Públicas, v.15 n.02, p.145-153, Jun./Dez. - 2016, ISSN 2317-7748. Disponível em:

https://sanare.emnuvens.com.br/sanare/article/view/1049/595. Acesso em 15 ago. 2020.

PEREIRA, Diego da Silva; MARTINS, Rodrigo Siqueira. Material de apoio Ubuntuca: sistema operacional, writer, impress, calc e internet. Natal-RN: Editora do IFRN, 2016.

PEREIRA, Vera Lucia de Souza. O Uso de Jogos, como Ferramenta para o Desenvolvimento do Raciocínio Lógico Matemático nas Séries Iniciais do Ensino Fundamental. Revista Psicologia \& Saberes, v. 9, n. 19, p. 157-171, 2020. ISSN 2595-6272. Disponível em: https://revistas.cesmac.edu.br/index.php/psicologia/article/view/1272. Acesso em 17 ago. 2020.

PEREIRA, Verônica Sales; DE LIMA, Roberta Valéria Guedes; MOREIRA, Jonathan Rosa. Contribuiç̃ões do uso das Tecnologias da Informação e Comunicação no processo de alfabetização das crianças do primeiro ano do ensino fundamental. PROJEÇão E DOCÊNCIA, v. 10, n. 2, p. 103-118, 2019. ISSN 2178-6275. Disponível em: http://revista.faculdadeprojecao.edu.br/index.php/Projecao3/article/view/1551/1199. Acesso em 17 ago. 2020.

PESCADOR, Cristina Maria. Ações de aprendizagem empregadas pelo nativo digital para interagir em redes hiper midiáticas tendo o inglês como língua franca. 2010. $142 \mathrm{f}$. Dissertação (Mestrado em Educação) Programa de Pós-Graduação em Educação. Universidade de Caxias do Sul, Caxias do Sul, 2010.

PESCADOR, Cristina Maria; VALENTINI, Carla Beatris. Inclusão digital em uma escola do campo: movimentos provocados a partir da implantação de uma política pública no modelo 1 : 1. Revista Iberoamericana de Educación, v. 79, n. 1, p. 135-154, 2019. https://doi.org/10.35362/rie7913409. Disponível em: https://rieoei.org/RIE/article/view/3409/4026. Acesso em 23 ago. 2020.

PINHEIRO, Liliane Monteiro; PINHEIRO, Viviani Monteiro. O programa Tux Paint no processo de letramento dos alunos do $3^{\circ}$ ano/9 em uma escola municipal em Bragança. 2017, 58f. Trabalho de Conclusão de Curso (Licenciatura em Computação) - Universidade Federal Rural da Amazônia, Plano Nacional de Formação de Professores, Pólo Augusto Corrêa, PA, 2017. 
PINTO, Janille Da Costa; MENEZES, Cláudia Celeste Lima Costa. O uso das tic's e sua influência na prática pedagógica de educação infantil: um estudo na creche municipal dom Eduardo no município de Ilhéus/BA. Seminário Gepráxis, Vitória da Conquista - Bahia Brasil, v. 6, n. 6, p. 1843-1861, 2017. Disponível em:

http://anais.uesb.br/index.php/semgepraxis/article/viewFile/7330/7107. Acesso em 17 ago. 2020.

PISCINATO, Milton Tadeu; DE OLIVEIRA, Gardênia Felis. DIFICULDADES DE APRENDIZAGEM. Revista de Pós-graduação Multidisciplinar, v. 1, n. 2, p. 57-64, 2017, e-ISSN 2594-4797. Disponível em: http://fics.edu.br/index.php/rpgm/article/view/574/633. Acesso em 17 ago. 2020.

POLICARPO, Lucas Micol; FUHR, Gabriel Tobias; LIBRELOTTO, Giovani R. Uma abordagem para apoio em laboratórios computacionais em escolas públicas de ensino infantil. Revista ComInG-Communications and Innovations Gazette, v. 4, n. 1, p. 1-10, 2019. ISSN: 2448-1904. Disponível em: https://periodicos.ufsm.br/coming/article/view/38072/pdf_final. Acesso em15 ago. 2020.

REZENDE, Mariana Vidotti. O conceito de letramento digital e suas implicações pedagógicas. Texto Livre Linguagem e Tecnologia, v. 9, n. 1, p. 94-107, 2016. ISSN 19833652. Disponível em:

http://www.periodicos.letras.ufmg.br/index.php/textolivre/article/view/10266/9615. Acesso em: 09 de nov. de 2019.

RHODEN, Juliana Lima Moreira; ZANCAN, Silvana. A perspectiva da abordagem qualitativa narrativa de cunho sociocultural: possibilidade metodológica na pesquisa em educação. Educação (UFSM), v. 45, n. 1, p. 1-22, 2020. ISSN 1984-6444. Disponível em: https://periodicos.ufsm.br/reveducacao/article/view/36867. Acesso em 19 ago. 2020.

SANTOS, Acácia Aparecida Angeli dos; MORAES, Mayara Salgado de; LIMA, Thatiana Helena. Compreensão de leitura e motivação para aprendizagem de alunos do ensino fundamental. Psicologia Escolar e Educacional, v. 22, n. 1, p. 93-101, 2018. ISSN 21753539. Disponível em: http://www.scielo.br/scielo.php?script=sci_serial\&pid=1413$\underline{8557 \& \operatorname{lng}=e n \& n r m=i s o}$. Acesso em 24 ago. 2020.

SANTOS, Fernanda Maria Almeida dos. Práticas de letramento digital para crianças: contribuições e novas perspectivas para o aprendizado da escrita, v. 1, n. 1, 1-22, 2015. ISSN 1984-1175. Disponível em: http://nehte.com.br/simposio/anais/Anais-Hipertexto2015/Pr\%C3\%A1ticas\%20de\%20letramento\%20digital\%20para\%20crian\%C3\%A7as.pdf. Acesso em 18 ago. 2020.

SANTOS, Lucivânia Bernardo dos. A utilização do computador como recurso didático pedagógico em uma creche do município de Garanhuns - PE. 2019. 29 f. Trabalho de Conclusão de Curso (Licenciatura em Pedagogia) - Unidade Acadêmica de Garanhuns, Universidade Federal Rural de Pernambuco, Garanhuns, 2019.

SANTOS, Verônica Gomes dos; ALMEIDA, Sandra Estefânia de and ZANOTELLO, Marcelo. A sala de aula como um ambiente equipado tecnologicamente: reflexões sobre formação docente, ensino e aprendizagem nas séries iniciais da educação básica. Revista Brasileira de Estudos Pedagógicos. [online]. 2018, v. 99, n. 252, p.331-349. ISSN 2176- 
6681. Disponível em: https://www.scielo.br/pdf/rbeped/v99n252/2176-6681-rbeped-99-252331.pdf. Acesso em 18 ago. 2020.

SEVERINO, Antônio Joaquim. Metodologia do trabalho científico. 24a ed. São Paulo: Cortez Editora, 2016. 317 p.

SILVA, Alessandra Dias Costa e, DOS SANTOS, Adevailton Bernardo. Sequência Didática para as Séries Iniciais: Água no Ambiente. 2017. 177f. Dissertação (Mestrado em Ensino de Ciências e Matemática). Programa de Pós-graduação em Ensino de Ciências e Matemática da Universidade Federal de Uberlândia, Uberlândia-MG. 2017.

THIOLLENT, Michel. Metodologia da pesquisa-ação. 18. ed. São Paulo: Cortez, 2011.

TONIN, Rosângela Prescendo; MATOS, Gisoneide Moreira. Ciranda Digital. Revista Com Censo: Estudos Educacionais do Distrito Federal, [S.1.], v. 5, n. 2, p. 171-176, abr. 2018. ISSN 2359-2494. Disponível em:

http://www.periodicos.se.df.gov.br/index.php/comcenso/article/view/352. Acesso em: 18 ago. 2020.

UFRGS. Tutorial Tux Paint. Disponível em: http://www.ufrgs.br/niee/livrosdigitais/livroazul/tutoriais/TuxPaint/tuxpaint_tutorial.pdf. Acesso em: 18 de nov. de 2019.

UFRPE; SME GARANHUNS. Guia de uso dos softwares livres disponibilizados nos computadores de mesa (desktops) das escolas municipais de Garanhuns. Garanhuns: UFRPE, 2019.

VIEIRA, Iúta Lerche. Tendências em pesquisas em gêneros digitais: focalizando a relação oralidade/escrita. In: ARAÚJO, J. C.; BIASI-RODRIGUES, B. (Org.) Interação na internet: novas formas de usar a linguagem. Rio de Janeiro: Lucerna, p.19-29. 2005.

VIEIRA, Tatiana Almeida. As concepções de linguagem no discurso do professor alfabetizador nas Séries Iniciais do Ensino Fundamental I. 2020. 117f - Dissertação (Mestrado) - Universidade Federal do Ceará, Programa de Pós-graduação em Linguística, Fortaleza (CE), 2020.

XABREGAS, Quezia Fragoso; BRASILEIRO, Tania Suely Azevedo. Política de Inclusão Digital: Possibilidades para Ensinar, Aprender e Incluir na Amazônia PARAENSE. Educamazônia-Educação, Sociedade e Meio. Ambiente, v. 23, n. 2, p. 537 556, 2019. ISSN 2318 - 8766. Disponível em: https://periodicos.ufam.edu.br/index.php/educamazonia/article/view/6778/4773. Acesso 23 ago. 2020.

Recebido em: 29 de junho de 2020. Aprovado em: 27 de agosto de 2020. 